\title{
Converting Waste Plastics into High Yield and Quality Carbon-Based Materials
}

\author{
Qinghong Kong, ${ }^{a}$ Ling Yang, ${ }^{b}$ Junhao Zhang, ${ }^{*, c, d}$ and Yibing $\mathrm{Cai}^{*, d}$ \\ ${ }^{a}$ School of the Environment and Safety Engineering, Jiangsu University, Zhenjiang, Jiangsu 212013, China \\ ${ }^{b}$ State Key Laboratory of Fire Science, University of Science and Technology of China, Hefei, Anhui 230026, China \\ ${ }^{c}$ School of Environmental and Chemical Engineering, Jiangsu University of Science and Technology, Zhenjiang, \\ Jiangsu 212003, China \\ ${ }^{d}$ Key Laboratory of Eco-textiles, Ministry of Education, Jiangnan University, Wuxi, Jiangsu 214122, China
}

\begin{abstract}
Recycling waste plastics including polypropylene, polyethylene, polyethylene terephthalate, polystyrene, etc, is a very important scientific, social and economic topic. Despite significant advances in recent years, approximately 400 million tons of waste plastics are still disposed by landfill. This is obviously not an effective solution due to plastic's non-biodegradable character. Aside from mechanical recycling, which turns waste plastics into new products, and thermal recycling, which releases the thermal energy through combustion of waste plastics, chemical recycling converts waste plastics into feedstock for chemicals/materials/fuels production. This article reviews previous work on the pyrolysis and catalytic decomposition route that converted plastics into carbon-based materials, which exhibited extraordinary physical and chemical properties. However, their production processes are both resource and energy-intensive. Therefore, recycling technologies for waste plastics are still at an early stage and more innovation in waste plastic recycling is needed.
\end{abstract}

Keywords waste plastics, converting, catalytic decomposition, carbon based materials

\section{Introduction}

Plastic materials are ubiquitous in our daily life and implemented in almost all domestic and industrial appliances. Especially with the industrial development, plastic consumption has drastically increased, primarily up to 400 million tons in 2016 , rising by over $5 \%$ per years. ${ }^{[1]}$ The enormous and escalating volume of waste plastics might cause severe negative environmental impact on human life. ${ }^{[2]}$ Plastic recycling has been employed to recover waste plastics and reprocess them into useful products. However, the recycling level is still very low, and the overall plastic recycling rate was approximately $8 \% .{ }^{[3]}$

Recently, the disposal of waste plastics has been also an important concern because of the high use of different plastics. ${ }^{[4]}$ The disposal technology for waste plastics mainly consists of three types: landfill, incineration and recycling. Despite significant advances in recent years, most waste plastics are still disposed by landfill, which is obviously not an effective solution due to plastic's non-biodegradable. ${ }^{[5]}$ Waste can be thought of as a resource reservoir, this becomes significant when the shortage of resources is considered. The most usual alternative is incineration accompanied by energy recovery, which often meets strong opposition due to the loss of raw materials and the risk emission of toxic compounds. ${ }^{[6]}$ Mechanical recycling of plastics into new products is therefore the preferred recovery route. ${ }^{[7]}$ However, only $15 \%-20 \%$ of waste plastics can be effectively recycled because it is sensitive to contaminated waste polymers. The problem of mixed plastics has been partially solved by separation technologies such as flotation, ${ }^{[7]}$ plasma gasification technology, ${ }^{[8]}$ and so on. However, these multistep recycling processes are not costeffective. Conversion of the used plastics into valuable chemicals or materials is an ideal alternative. Several methods for the recycling of waste plastics have been proposed, of which pyrolysis is a promising approach with potential applications. For example, thermal cracking of the polymers to give low molecular weight products, ${ }^{[9,10]}$ but un- fortunately gives a very broad range of products and requires high temperatures, even up to $900{ }^{\circ} \mathrm{C} .{ }^{[11,12]}$ The addition of catalyst is expected to reduce decomposition temperature, to promote decomposition speed, and to modify the decomposition products. ${ }^{[13-15]}$ It would be desirable to convert these waste plastics into more valuable carbon-based materials, such as carbon nanotubes (CNTs), carbon spheres, porous carbon and carbon based composites. Importantly, these carbon-based materials may have further potential applications in several fields, such as energy storage field, polymer composite field, catalytic field, etc.

\section{Waste plastics as low cost feedstocks for carbon materials}

The concept of synthesizing CNTs using solid polymer was firstly reported about 21 years ago. ${ }^{[16]}$ There have been numerous efforts on further advancing such synthesis route of low cost CNTs. Work have been done about types of plastics, conversion processes, growth conditions, catalysts, and quantities and qualities of versions, and the work examined processes based on the reactors types alone, such as autoclave, fix bed, moving bed, fluidized bed, etc. Instead, the scientists hereby focus on both the common and on the differentiating features of the existing waste-plastics-to-carbon conversion processes. Thereby, such conversions may be classified into two categories: (1) one-pot conversion where synthesis of carbon-based materials occurs upon the in situ formation of carbon feedstocks from waste plastics; (2) stepwise conversion where synthesis of carbon-based materials occurs after the formation of carbon feedstocks from waste plastics. Several typical carbon-based materials are summarized in following sections, including CNTs, porous carbon materials, and carbon-based composites.

\footnotetext{
* E-mail: jhzhang6@mail.ustc.edu.cn Received August 16, 2017; accepted September 1, 2017.
} 


\section{Preparation of carbon nanotubes}

The outstanding mechanical, electrical and chemical properties of CNTs have motivated extensive research for their synthesis, functionalization and potential application. ${ }^{[17]}$ Particularly, in the field of synthesis, various methods have been developed for the synthesis of CNTs such as arc discharge, ${ }^{[18]}$ pyrolysis, ${ }^{[19]}$ laser vaporization ${ }^{[20]}$ and thermal chemical vapor deposition. ${ }^{[21]}$ Catalytic decomposition of hydrocarbons is a promising means to produce CNTs on a large scale. ${ }^{[22,23]}$ Synthesis of CNTs through thermal decomposition of polymer/catalysts has also been reported. Maksimova et al. ${ }^{[24,25]}$ prepared CNTs with a diameter of about $20 \mathrm{~nm}$ by decomposition of polyethylene (PE) and polyvinyl alcohol (PVA) using iron catalysts.

Polymeric materials are frequently used as carbon sources for the synthesis of CNTs. For example, Tang et al. synthesized CNTs in large quantities by burning a PP/Ni/MMT composite in the atmosphere. ${ }^{[26-28]}$ Chen et al. synthesized CNTs, chestnut-like CNTs spheres and carbon nanospheres from catalytic pyrolysis of polypropylene (PP) using different catalyst precursors (Figure 1). ${ }^{[29,30]}$ In their methods, it is necessary that catalyst precursors were mixed with PP and clay, then such nanocomposites were burned to obtain CNTs. In our previous work, CNTs with various structures were prepared by catalytic decomposition of waste plastics using stainless steel autoclave as reactor. For example, straight and helical CNTs with diameter from 20 to $60 \mathrm{~nm}$ were synthesized through catalytic decomposition of PE. The yield of CNTs was over $80 \%$ including about $5 \%$ helical CNTs. ${ }^{[31]}$ CNTs with larger diameter of about 160 $\mathrm{nm}$ were synthesized through catalytic decomposition of PP and maleated PP (MA-PP) using Ni as catalysts. The toxic or corrosive reagents have been completely avoided. Reaction temperature, Ni catalysts, and MA-PP played key roles in synthesis of the larger diameter CNTs. ${ }^{[32]}$ Microspheres assembled from carbon nanotubes (MCNTs) and CNTs were synthesized using waste PP as carbon source and MA-PP as compatibilizer and carbon source, and ferrocene as catalyst precursor without pre-mixing all components. The BET surface area of the MCNTs prepared at $600{ }^{\circ} \mathrm{C}$ is about twice as that of CNTs prepared at $700{ }^{\circ} \mathrm{C}$, which results in higher catalytic activity of MCNTs based catalyst for the preparation of methanol and DMET from DME ${ }^{[33]}$ Therefore, using waste plastics as inexpensive feedstocks can contribute to the cost reduction of CNTs production, which may accelerate CNTs large-scale use in consumer/industrial products.

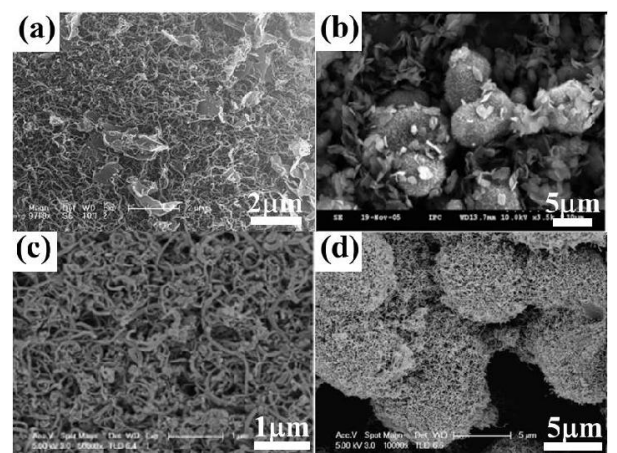

Figure 1 SEM images: (a) CNTs by burning a PP/Ni/MMT composite in the atmosphere; ${ }^{[27]}$ (b) Chestnut-like carbon nanotube spheres by heating the PP/OMMT/NF composites; ${ }^{[29]}$ (c) Straight and helical CNTs through catalytic decomposition of PE; ${ }^{[31]}$ (d) MCNTs by catalytic decomposition of PP and MA-PP. ${ }^{[33]}$

\section{Preparation of carbon spheres}

In the past decade, carbon spheres have been attracting the interest of researcher community due to their interesting physicochemical properties and applicability as reinforcement materials for rubber, ${ }^{[34]}$ supports for catalysts, ${ }^{[35]}$ lubricating materials and in fuel cells or secondary lithium ion batteries. ${ }^{[36]}$ Many techniques such as chemical vapor deposition, ${ }^{[37]}$ solvothermal synthesis, ${ }^{[38]}$ carbonization $^{[39]}$ and $\operatorname{arc-discharge}^{[40]}$ have been employed for the preparation of carbon spheres. Many of them utilized the chemical reagent as carbon source and metal as catalyst agent. One of the main disadvantages of such method is the conversion of metal catalyst into their respective metal salts during synthesis and post synthesis treatment, which increases the cost, and causes the environmental issue. Therefore, utilization of waste plastics for preparing carbon microspheres is explored widely.

Well-shaped carbon spheres in micrometer dimensions were prepared by pyrolyzing waste poly(ethyleneterephthalate) (PET) in supercritical $\mathrm{CO}_{2}$. The yield of carbon microspheres was increased as the reaction temperature increased and the reaction time was prolonged. Carbon microspheres were obtained in $47.5 \%$ yield as the reaction occurred at $650^{\circ} \mathrm{C}$ for $9 \mathrm{~h}$. As anodes for LIBs, it exhibits a first discharge capacity of $504.9 \mathrm{~mA} \cdot \mathrm{h} \cdot \mathrm{g}^{-1}$ at $100 \mathrm{~mA} \cdot \mathrm{g}^{-1}$ and maintains a capacity retention of $40 \%$ after the $20^{\text {th }}$ cycle (Figure 2 ) ${ }^{[41]} \mathrm{Pol}$ et al. presents an environmentally benign, solvent-free autogenic process that converts various waste plastics including PE, PET, polystyrene (PS), or their mixtures into carbon microspheres. The room temperature paramagnetism in carbon microspheres prepared from waste PE, and PS was further studied by electron paramagnetic resonance. The conducting and paramagnetic nature of carbon microspheres holds promise for their potential applications in toners, printers, paints, batteries, lubricants, and tires. ${ }^{[42]}$ An efficient, solvent-free, catalyst-free approach was reported for the synthesis of carbon microspheres by thermal decomposition of waste PET in a closed reactor under autogenic pressure yielded exceptionally hard spherical (2 to $10 \mu \mathrm{m}$ diameters) solid carbon bodies, with the average tensile strength for a single ( $\sim 6 \mu \mathrm{m}$ diameter $)$ carbon sphere calculated to be $8.30 \pm 0.69 \mathrm{GPa}^{[43]}$ A solvent free approach with catalyst was developed to produce large scale of carbon microspheres with $100 \%$ purity, using various waste plastics, such as PP, PE. Without any post treatment, the carbon spheres have been successfully utilized as the template for the synthesis of nanocrystalline $\mathrm{CuO}$ hollow spheres. ${ }^{[4]}$

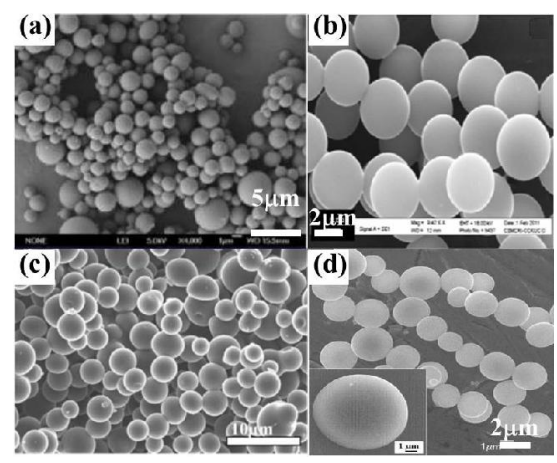

Figure 2 SEM images of various carbon spheres: (a) dissociating PET in a supercritical $\mathrm{CO}_{2}$ system; ${ }^{[41]}$ (b) thermal decomposition of waste $\mathrm{PP} ;{ }^{[44]}$ (c) thermal decomposition of waste $\mathrm{PE} ;{ }^{[42]}$ thermal decomposition of waste PET in a closed reactor. ${ }^{[43]}$

\section{Preparation of porous carbon materials}

Due to large surface areas, good chemical stability, high electronic conductivity, porous carbon materials are of great interest for their applications as electrode materials, absorbents for separation, and supports for catalysts. ${ }^{[45-47]}$ Currently, there are several strategies to prepare porous carbon materials from various precursors, such as biomass, ${ }^{[48]}$ polymers, ${ }^{[49]}$ metal-organic frameworks, ${ }^{[50]}$ carbide materials, ${ }^{[51]}$ etc. To reduce the cost, many biomasses were converted into porous carbon. For example, $\mathrm{Yu}$ et al. prepared porous carbon with high specific surface area of $441.1 \mathrm{~m}^{2} \cdot \mathrm{g}^{-1}$ by carbonization and $\mathrm{CO}_{2}$ activation of cattail biomass. ${ }^{[52]}$ 
To mitigate the impact on the environment and reduce the cost of porous carbon, upcycling waste plastics into porous carbon is very necessary. Yang et al. prepared mesoporous carbon with BET surface area of $1251 \mathrm{~m}^{2} \cdot \mathrm{g}^{-1}$ and an effective pore size of $3.66 \mathrm{~nm}$ by a chemical degradation of waste PS beverage packaging using ordered mesoporous silica as a hard template (Figure 3). ${ }^{[53]}$ Gong et al. successfully carbonized real-world mixed waste plastics containing PP, PE and PS into high value-added porous carbon nanosheets (PCNSs). The PCNSs showed a high specific surface area $\left(2315.0 \mathrm{~m}^{2} \cdot \mathrm{g}^{-1}\right)$ and large pore volume $\left(3.32 \mathrm{~cm}^{3} \cdot \mathrm{g}^{-1}\right)$ with abundant surface functional groups. More importantly, it was demonstrated that the PCNSs exhibited fast adsorption, an unprecedented adsorption capacity and excellent recyclability for the removal of $\mathrm{MB}$ from waste water. ${ }^{[54]}$ Uniform mesoporous hollow carbon spheres (HCSs) were also efficiently prepared through the carbonization of mixed plastics consisting of PP, PE and PS under the combined catalysis of OMMT/ $/ \mathrm{Co}_{3} \mathrm{O}_{4}$. The results indicated that OMMT not only promoted the dispersion of $\mathrm{Co}_{3} \mathrm{O}_{4}$ in the mixed plastics, which favored to control the diameter of HCSs, but also promoted the degradation of mixed plastics into light hydrocarbons and aromatics, which facilitated the growth of HCSs. ${ }^{[55]}$ Chen et al. reported that halogen-containing plastics have been converted into nanoporous carbon using zinc powder as an efficient hard template. The sample that is obtained by carbonizing polytetrafluoroethene (PTFE) and zinc powder (the mass ratio of $1: 3$ ) at $700{ }^{\circ} \mathrm{C}$ has large BET surface area of $800.5 \mathrm{~m}^{2} \cdot \mathrm{g}^{-1}$ and high total pore volume of $1.59 \mathrm{~cm}^{3} \cdot \mathrm{g}^{-1}$, also delivering excellent specific capacitance of $313.7 \mathrm{~F} \cdot \mathrm{g}^{-1}$ at $0.5 \mathrm{~A} \cdot \mathrm{g}^{-1}$. Moreover, it exhibits a superior cycling stability with high capacitance retention of $93.10 \%$ after cycling 5000 times. ${ }^{[56]}$

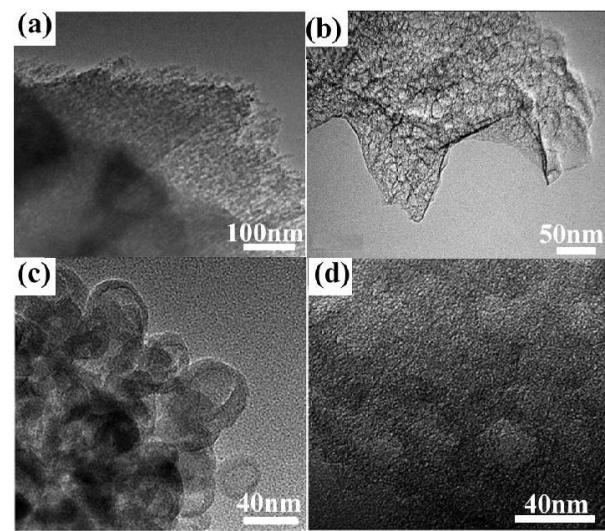

Figure 3 TEM images of various porous cabon: (a) chemical degradation of waste PS; ${ }^{[53]}$ (b) carbonizing halogen-containing PTFE; ${ }^{[56]}$ (c) upcycling waste mixed plastic using OMMT/ $\mathrm{Co}_{3} \mathrm{O}_{4}$ as catalysis $;{ }^{[55]}$ (d) carbonizing mixed waste plastics using $\mathrm{KOH}$ activation. ${ }^{[54]}$

\section{Preparation of carbon based composites}

Recently, carbon and metal oxides composites have attracted tremendous interest owing to their unique characteristics that cannot be obtained in conventional materials. ${ }^{[57-59]}$ Carbon and metal oxide composites have drawn attention due to its wide applications, including electrode materials, ${ }^{[60]}$ catalysts,${ }^{[61]}$ sensors, ${ }^{[62]}$ environment protection, ${ }^{[63]}$ magnetic storage media, ${ }^{[64]}$ and so on.

There is a strong need to develop a method for recycling the massive amount of waste plastics to prepare carbon based composites Feng et al. prepared mesoporous magnetic carbon material by catalytic carbonization of waste PP from car bumper. The final carbon material exhibits a graphitic carbon structure in high yield and interesting magnetic properties, which showed excellent performance in treating polluted water. ${ }^{[65]}$ In our previous work, waste plastics were converted to prepare a series of carbon based composites.
One-dimensional $\mathrm{Fe}_{3} \mathrm{O}_{4} @ \mathrm{C}$ composites were prepared by catalytic decomposition of waste $\mathrm{PE}$ using ferrocene as catalyst under the aid of $\mathrm{H}_{2} \mathrm{O}$ or $\mathrm{NH}_{4} \mathrm{HCO}_{3}$, which possess well acid resistance (Figure 4). ${ }^{[66,67]} \mathrm{Fe}_{3} \mathrm{O}_{4} @ \mathrm{C}$ composites with a "pine-tree-leaf" structure were prepared by catalytic pyrolysis of waste $\mathrm{PE}$, which exhibits particular ferromagnetism. ${ }^{[68]}$ Besides, $\mathrm{Fe}_{3} \mathrm{O}_{4} @ \mathrm{C}$ composites with firecracker-like structures were prepared by the catalytic decomposition of polyamide with controlling the reaction temperature and amount of $\mathrm{NH}_{4} \mathrm{HCO}_{3}$, which also possessed well acid resistance. ${ }^{[69]}$ We also introduce a creative method to convert waste PP to sponge-like $\mathrm{Fe} / \mathrm{CNTs}$ nanocomposites by manipulating the formation of carbon deposition with absence of $\mathrm{O}_{2}$ in closed reactor. The BET surface area of $\mathrm{Fe} / \mathrm{CNTs}$ nanocomposites is calculated to be $197.6 \mathrm{~m}^{2} \cdot \mathrm{g}^{-1}$, and the BJH adsorption cumulative volume of pores is up to 0.2860 $\mathrm{cm}^{3} \cdot \mathrm{g} .{ }^{[70]}$

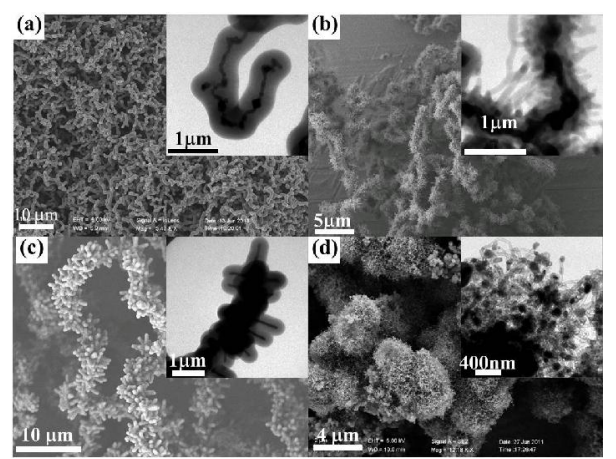

Figure 4 FESEM and TEM images: (a) One-dimensional $\mathrm{Fe}_{3} \mathrm{O}_{4} @ \mathrm{C}$ composites by catalytic decomposition of waste $\mathrm{PE}$; ${ }^{[6]}$ (b) $\mathrm{Fe}_{3} \mathrm{O}_{4} @ \mathrm{C}$ composites with a "pine-tree-leaf" structure by catalytic pyrolysis of waste $\mathrm{PE} ;{ }^{[68]}$ (c) $\mathrm{Fe}_{3} \mathrm{O}_{4} @ \mathrm{C}$ composites with firecracker-like structures by the catalytic decomposition of polyamide; ${ }^{[69]}$ (d) Fe/CNTs nanocomposites by catalytic pyrolysis of waste PP. ${ }^{[70]}$

\section{Conclusions}

In summary, upcycling waste plastics into high value carbon materials is indeed a sustainable solution with a promising future as it allows for conversion of post-consumer products to value-added products and can help alleviate the burden of solid wastes on the environment. Although the entire process would require optimization, making carbon based materials with substantially reduced contaminants using waste plastics is a desirable way of recycling wasted plastics.

\section{Acknowledgement}

The work was financially supported by the Natural Science of Foundation of China (No. 51603091), the Natural Science Foundation of Jiangsu Province (No. BK 20150505), the Open Project Program of Key Laboratory of Eco-textiles, Ministry of Education, Jiangnan University (No. KLET1609), and the Opening Project of State Key Laboratory of Fire Science (No. HZ2015-KF07).

\section{References}

[1] Chen, X. Y.; Cheng, L. X.; Deng, X.; Zhang, L.; Zhang, Z. J. Ind. Eng. Chem. Res. 2014, 53, 6990 .

[2] Salmiaton, A.; Garforth, A. Waste Manage. 2007, 27, 1891.

[3] The data was taken from U.S. Environmental Protection Agency, http://www.epa.gov/epawaste/conserve/materials/plastics.htm.

[4] Zhou, C. W.; Levendis, Y. A. J. Appl. Polym. Sci. 2014, 131, 1001.

[5] Ross, S.; Evans, D. J. Cleaner Prod. 2003, 11, 561.

[6] Wager, P. A.; Schluep, M.; Muller, E. Environ. Sci. Technol. 2012, 46, 
628

[7] Fraunholcz, N. Miner. Eng. 2004, 17, 261.

[8] Park, H. S.; Kim, C. G.; Kim, S. J. J. Ind. Eng. Chem. 2006, 12, 216.

[9] Kang, B. S.; Kim, S. G.; Kim, J. S. J. Anal. Appl. Pyrolysis 2008, 81, 7.

[10] Al-Salem, S. M.; Lettieri, P.; Baeyens, J. R. Waste Manag. 2009, 29, 2625.

[11] Ouiminga, S. K.; Rogaume, T. Sougoti, M. ; Commandre, J. M.; Koulidiati, J. J. Anal. Appl. Pyrolysis 2009, 86, 260.

[12] Jung, S. H.; Cho, M. H.; Kang, B. S.; Kim, J. S. Fuel Process Technol. 2010, $91,277$.

[13] Insura, N.; Onwudili, J. A.; Williams, P. T. Energ. Fuel 2010, 24, 4231.

[14] Lu, A. H.; Li, W. C.; Salabas, E. L.; Spliethoff, B. Chem. Mater. 2006, 18,2086

[15] Mullen, C. A.; Boateng, A. A.; Mihalcik, D. J.; Goldberg, N. M. Energ Fuel. 2011, 25, 5444.

[16] Cho, W. S.; Hamada, E.; Kondo, Y.; Takayanagi, K. Appl. Phys. Lett. 1996, 69, 278.

[17] Lei, T.; Chen, X. Y.; Pitner, G.; Philip Wong, H. S. J. Am. Chem. Soc. 2016, 138,802 .

[18] Sano, N. Mater. Chem. Phys. 2004, 88, 235.

[19] Hu, Z. D.; Hu, Y. F.; Chen, Q.; Peng, L. M. J. Phys. Chem. B 2006, 110, 8263.

[20] Blackburm, J. L.; Yan, Y.; Engtrakul, C.; Parilla, P. A.; Jones, K.; Gennett, T.; Dillon, A. C.; Heben, M. J. Chem. Mater. 2006, 18, 2558.

[21] Bondi, S. N.; Lackey, W. J.; Johnson, R. W.; Wang, Z. L. Carbon, 2006, 44, 1393.

[22] Jeong, H. J.; Kim, K. K.; Jeong, S. Y.; Park, M. H.; Yang, C. W.; Lee, Y. H. J. Phys. Chem. B 2004, 108, 17695.

[23] Lyu, S. C.; Liu, B. C.; Lee, S. H.; Park, C. Y.; Kang, H. K.; Yang, C. W.; Lee, C. J. J. Phys. Chem. B 2004, 108, 1613.

[24] Maksimova, N. I.; Krivoruchko, O. P.; Mestl, G.; Zaikovskii, V. I.; Chuvilin, A. L. Salanov, A. N.; Burgina, E. B. J. Mol. Catal. A Chem. 2000, 158,301 .

[25] Krivoruchko, O. P.; Maksimova, N. I.; Zaikovskii, V. I.; Salanov, A. N. Carbon 2000, 38, 1075.

[26] Tang, T.; Chen, X. C.; Meng, X. Y.; Chen, H.; Ding, Y. P. Angew. Chem. Int. Ed. 2005, 44, 1517.

[27] Jiang, Z. W.; Song, R. J.; Bi, W. G.; Lu, J.; Tang, T. Carbon 2007, 45, 449.

[28] Song, R J.; Jiang, Z. W.; Bi, W. G.; Cheng, W. X.; Lu, J.; Huang, B. T.; Tang, T. Chem. Eur. J. 2007, 13, 3234.

[29] Chen, X. C.; He, J. H.; Yan, C. X.; Tang, H. M. J. Phys. Chem. B 2006, $110,21684$.

[30] Chen, X. C.; Wang, H.; He, J. H. Nanotechnology 2008, 19, 325607.

[31] Kong, Q. H.; Zhang J. H. Polym. Degrad. Stabil. 2007, 92, 2005.

[32] Zhang, J. H.; Li, J.; Cao, J.; Qian, Y. T. Mater. Lett. 2008, 62, 1839.

[33] Zhang, J. H.; Du, J.; Qian, Y. T.; Xiong, S. L. Mater. Res. Bull. 2010, 45, 15 .

[34] Ismail, H.; Freakley, P. K.; Sheng, E. Eur. Polym. J. 1995, 31, 1049.

[35] Yang, R.; Qiu, X.; Zhang, H.; Li, J.; Zhu, W.; Wang, Z.; Huang, X. Carbon 2005, 43, 11 .

[36] Li, W.; Chen, D.; Li, Z.; Shi, Y.; Wan, Y.; Wang, G.; Jiang, Z.; Zhao, D. Carbon 2007, 45, 1757 .

[37] Wang, P.; Wei, J.; Huang, B.; Qin, X.; Yao, S.; Zhang, Q.; Wang, Z.; Xu, G.; Jing, X. Mater. Lett. 2007, 61, 4854.

[38] Sawant, S. Y.; Somani, R. S.; Newalkar, B. L.; Choudary, N. V.; Bajaj, H. C. Mater. Lett. 2009, 63, 2339.

[39] Yao, J.; Wang, H.; Liu, J.; Chan, K. Y.; Zhang, L.; Xu, N. Carbon 2005, 43,1709
[40] Qiao, W. M.; Song, Y.; Lim, S. Y.; Hong, S. H.; Yoon, S. H.; Mochida I.; Imaoka, T. Carbon 2006, 44, 187.

[41] Wei, L. Z.; Yan, N.; Chen, Q. W. Environ. Sci. Technol. 2011, 45, 534

[42] Pol, V. G. Environ. Sci. Technol. 2010, 44, 4753.

[43] Pol, S.V.; Pol, V. G.; Sherman, D.; Gedanken, A. Green Chem. 2009, 11, 448.

[44] Sawant, S. Y.; Somani, R. S.; Panda, A. B.; Bajaj, Han. C. ACS Sustain Chem. Eng. 2013, 1, 1390.

[45] Niu, J.; Shao, R.; Liang, J. J.; Dou, M. L.; Li, Z. L.; Huang, Y. Q.; Wang, F. Nano Energy 2017, 36, 322.

[46] Fan, H. L.; Ran, F.; Zhang, X. X.; Song, H. M.; Jing, W. X.; Shen, K. W.; Kong, L. B.; Kang, L. Electrochim. Acta 2014, 138, 367.

[47] Chen, C.; Luo, C.; Zhang, X. H.; Li, Y. P.; Huang, J. L.; Chen, B. Q.; Chen, J. H. New J. Chem. 2017, 41, 7432.

[48] Liu, Y. C.; Huang, B. B.; Lin, X. X.; Xie, Z. L. J. Mater. Chem. A 2017, 5,13009 .

[49] Xiao, Z. C.; Kong, D. B.; Liang, J. X.; Wang, B.; Iqbal, R.; Yang, Q. H.; Zhi, L. J. Carbon 2017, 116, 633.

[50] Ahn, S. H.; Klein, M. J.; Manthiram, A. Adv. Energy Mater. 2017, 7, 1601979

[51] Cheng G.; Long, D. H.; Liu, X. J.; Ling, L. C. New Carbon Mater. 2009 24, 243

[52] Yu, M.; Han, Y. Y.; Li, J.; Wang, L. J. Chem. Eng. J. 2017, 317, 493.

[53] Yang, J.; Jin, Y. X.; Yu, X. P.; Yue, Q. F. J. Sol-Gel. Sci. Technol. 2017, $83,413$.

[54] Gong, J.; Liu, J.; Chen, X. C.; Jiang, Z. W.; Wen, X.; Mijowska, E.; Tang, T. J. Mater. Chem. A 2015, 3, 341.

[55] Gong, J.; Liu, J.; Jiang, Z. W.; Chen, X. C.; Wen, X.; Mijowska, E.; Tang, T. Appl. Catal. B: Environ. 2014, 152-153, 289.

[56] Cheng, L. X.; Zhu, Y. Q.; Chen, X. Y; Zhang, Z. J. Ind. Eng. Chem. Res 2015, 54, 9948

[57] Bailon-Garcia, E.; Elmouwahidi A.; Carrasco-Marin, F.; Perez-Cadenas, A. F.; Maldonado-Hodar, F. J. Appl. Catal. B: Environ. 2017, 217, 540

[58] Zhang, K. C.; Gao, X. B.; Zhang, Q.; Li, T. P.; Chen, H.; Chen, X. F. J. Alloy. Compd. 2017, 721, 268.

[59] Wang, Y. N.; Fu, N. Q; Ma, P.; Fang, Y. Y.; Peng, L. M.; Zhou, X. W.; Lin, Y. Appl. Surf. Sci. 2017, 419, 670.

[60] Fang, S.; Tong, Z. K.; Zhang, X. G. Chem. Eng. J. 2017, 322, 188

[61] Jiang, Z. F.; Qian, K.; Zhu, C. Z.; Sun, H. L.; Wan, W. M.; Xie, J. M.; Li, H. M.; Wong, P. K.; Yuan, S. Q. Appl. Catal. B: Environ. 2017, 210, 194.

[62] Yin, H. Y.; Cui, Z. Z.; Wang, L.; Nie, Q. Sensor. Actuat. B-Chem. 2016, $222,1018$.

[63] Zhong, L.S.; Hu, J.S.; Liang, H.P.; Song, W.G.; Wan, L. J. Adv. Mater 2006, 18, 2426.

[64] Daou, T.J.; Grenche, J.M.; Pourroy, G.; Buathong, S.; Derory, A.; Bouillet, C.U.; Donnio, B.; Guillon, D.; Begin-Colin, S. Chem. Mater. 2008, 20,5869 .

[65] Feng, J. D.; Gong, J.; Wen, X.; Tian, N. N.; Chen, X. C.; Mijowska, E.; Tang, T. RSC Adv. 2014, 4, 26817.

[66] Zhang, J. H.; Yan, B.; Wan, S.; Kong, Q. H. Ind. Eng. Chem. Res. 2013, 52,5708 .

[67] Zhang, J. H.; Du, J.; Ma, D. K.; Xi, G. C.; Hu, X. B.; Qian, Y. T. Solid State Commun. 2007, 144, 168

[68] Zhang, J. H.; Yan, B.; Zhang, F. CrystEngComm 2012, 14, 3451.

[69] Zhang, J. H.; Yan, B.; Wu, H.; Kong, Q. H. RSC Adv. 2014, 4, 6991.

[70] Zhang, J. H.; Zhang, L. M.; Yang, H.; Kong, Q. H.; Liu, Y. J.; Yuan, A. H. CrystEngComm 2014, 16, 8832 